\title{
15 Edición “independiente” y bibliodiversidad. Reflexiones
}

Como he expuesto en 1.3, la industria cultural transnacional durante los años 90 del siglo pasado fue delineando un escenario que la bibliografía caracterizó y sigue caracterizando como "concentración". Textos de García Canclini, de Yúdice, de Escalante Gonzalbo, de Sarlo, como ya he comentado, han abordado el fenómeno. También una serie de testimonios y reflexiones en primera persona, como The Business of Books: How the International Conglomerates took over Publishing and changed the Way we Read (2000), de André Schiffrin, o Los mercaderes en el templo de la literatura (2004), de Germán Gullón. Lo cierto es que, desde la abrupta apertura de los mercados nacionales a partir de la Caída del Muro, las industrias editoriales locales de mediano porte fueron absorbidas por grandes conglomerados multimedios que no solo disponen de los recursos económicos necesarios sino también de la infraestructura que funciona de soporte para la selección, publicación, jerarquización y puesta en circulación de literatura a nivel internacional, esto es, distribuidoras, cadenas de librerías, medios de prensa e instituciones de padrinazgo. ${ }^{1}$ Este proceso ha significado que la tensión entre el polo autónomo y el heterónomo del campo literario se inclinara en favor del segundo y, de manera concomitante, de su lógica. Para el caso de América Latina esta evolución se expresa en un escenario actual en el que el mercado del libro internacional, incluido el de literatura de ficción -la que llega seleccionada en España y la que va a entrar en el circuito internacional vía España-, aparece controlado, fundamentalmente, por dos grupos: Planeta y Bertelsmann. Estos dos grupos y, en parte, también Anagrama son, así, los principales agentes en lo que refiere a la inserción de literatura latinoamericana en mercados extranjeros, al establecimiento de autores, “corrientes” y novelas, y a la creación de públicos internacionales correspondientes. De modo que, según mis hipótesis, la lógica heterónoma promovida por los conglomerados transnacionales es la que domina y regula el funcionamiento de la literatura latinoamericana mundial, entendida, de acuerdo con el modelo de Damrosch,

\footnotetext{
1 "Los grupos concentran todas las áreas de especialización que en el pasado permitían delimitar el campo, incluyendo la distribución de la información y los medios de legitimación -edición, premios, medios de comunicación, manuales escolares-. Si son juez y parte, si tienen el 'monopolio de la producción, la reproducción y la manipulación legítimas de los bienes simbólicos y del poder correlativo de imposición legítima' (Bourdieu 2010, 145), ¿cómo se determina la validez de lo literario?”, reflexiona José Ignacio Padilla sobre el punto (“Independientes" 247).
}

Ә Open Access. (C) 2019 Jorge J. Locane, published by De Gruyter. (c) BY-NC-ND This work is licensed under the Creative Commons Attribution-NonCommercial-NoDerivatives 4.0 License. https://doi.org/10.1515/9783110622096-015 
simplemente como la que circula más allá de su origen nacional. Difícilmente podría ser de otra manera porque tal tipo de "circulación" tiene un costo que solo puede ser cubierto bajo premisas de gran inversión, bajo riesgo y rápido retorno. ${ }^{2}$

Sin embargo, desde comienzo de los años 00 y en paralelo a la bibliografía que acabo de retomar, vamos a ver aparecer textos, libros e incluso manifiestos que abordan el fenómeno de la publicación denominada "independiente" y lo exaltan como un modo de producción opuesto al de la concentración. Puedo nombrar textos como La edición independiente como herramienta protagónica de la bibliodiversidad (2008), de Gilles Colleu, publicado originalmente en francés en el 2006; Bibliodiversity: A Manifesto for Independent Publishing, de Susan Hawthorne, del 2014, y, más concentrados en América Latina, dossiers de revistas como "Comunidades y relatos del libro en América Latina", en Orbis Tertius, del 2015; y, del mismo año, "Nuevas experiencias editoriales y literaturas contemporáneas", en Cuadernos LÍRICO. También volúmenes y publicaciones colecticas como las actas del 1er encuentro de editores independientes de América Latina (2000), Los editores independientes del mundo latino y la bibliodiversidad (2007), el ya comentado Encuentro chileno de editoriales independientes (2012) y otros como Independientes, ¿de qué? Hablan los editores de América Latina (2016), editado por Hernán López Winne y Víctor Malumián, o A pulmón o sobre cómo editar de forma independiente en español (2017), compilado por Ana Gallego Cuiñas y Erika Martínez. De modo que lo que tenemos ahora es un desdoblamiento en dos grandes categorías fundamentalmente opuestas y no del todo sometidas a examen; dos términos que hasta el momento yo mismo he utilizado, conscientemente, sin establecer mayores precisiones: concentración, como la lógica editorial que impulsan los grandes conglomerados, e "independencia", como un modo de gestión que pretende conceptualizar a la literatura por su valor intrínseco. En su conjunto, se trata del fenómeno que, para el caso argentino, Malena Botto ha caracterizado como "polarización". ${ }^{3}$ Esta ramificación conceptual implica una serie de complejidades que es lo que, dentro de lo posible, quiero abordar en este apartado.

Antes de eso, introduzco rápidamente una tercera categoría que ya he adelantado y que aparece comprometida en los títulos que acabo de mencionar: la de bibliodiversidad. Este término acompaña la evolución reciente de la industria editorial, tensionada entre la concentración y la independencia, y cuenta con un sostenido aval institucional, por ejemplo, por parte de la UNESCO, una

$2 \mathrm{Al}$ respecto, Jorge Herralde dice que "La concentración tiende a esquivar riesgos, a repetir fórmulas, lógicamente, ya que las inversiones son enormes” (“La edición...” 163).

3 Para una perspectiva regional, véase Padilla “¿Circuitos...”. 
elaboración conceptual alimentada por la publicación homónima y una red gremial centralizada desde el 2002 en la Alianza internacional de editores independientes ${ }^{4}$ con diversas expresiones nacionales -como LIBRE en Brasil, EDIN en Chile, REIC en Colombia, EIE en Ecuador, AEMI en México, ALPE en Perú y EDINAR en Argentina- que ejercen de lobby para la implementación de políticas culturales destinadas a proteger la publicación independiente.

Tendríamos, por lo tanto, una tríada constituida por la concentración como fenómeno concomitante a la globalización (neoliberal), la independencia como modo de resistencia a la lógica heterónoma y la bibliodiversidad como herramienta conceptual para alentar la protección y multiplicación de catálogos independientes.

Voy a dejar de lado el primer elemento porque ya lo he abordado para concentrarme más bien en los dos restantes, en la publicación "independiente" y en la bibliodiversidad, a partir de un axioma que sostiene, todavía de manera muy laxa, que la publicación "independiente" es el lugar de la experimentación, de la autonomía y de una efectiva heterogeneidad, esto es, de las literaturas locales que, en su conjunto, constituyen el corpus de lo que yo denomino literatura pluriversal (cfr. Locane "Más allá..."), entendido como el que reúne las declinaciones que problematizan -lo que se podría llamar- la gramática del consenso entre mercado y producción cultural y componen un paisaje descentrado y plural. Me interesa, sin embargo, empezar por interrogar los conceptos en juego.

Empecemos por la "independencia". En algún sentido, podría pensarse emparentada con o derivada del modo productivo que Ángel Rama presentó a principios de los años 80 como propio de las "editoriales culturales", por opuesto al de las "editoriales comerciales"; sin embargo, creo que los cambios históricos y la polarización de los modos de gestión cultural no permiten establecer tan fácilmente esa genealogía. Se podría pensar, como, por ejemplo, propone Jorge Herralde, que una editorial independiente es aquella en la que editor y dueño

4 El sitio web oficial del organismo informa que "La Alianza internacional de editores independientes es un colectivo profesional que reúne a más de 550 editoriales independientes presentes en 52 países del mundo. Creada como una asociación en 2002, está organizada en 6 redes lingüísticas (anglófona, arabófona, francófona, de habla castellana, lusófona y persanófona). Los miembros de la Alianza son editoriales o colectivos nacionales de editoriales. La totalidad de las actividades de la Alianza tienden a promover y lograr que viva la bibliodiversidad (la diversidad cultural aplicada al mundo del libro).

En el marco de sus misiones, la Alianza creó entonces un Observatorio de la bibliodiversidad, que recopila las investigaciones, análisis y herramientas de medición producidas en el seno de la Alianza, dirigidas a profesionales y poderes públicos. El Observatorio tiene como objetivos evaluar y reforzar la bibliodiversidad en las diferentes regiones del planeta”. 
aparecen encarnados por una misma persona. El editor, en este caso, no “depende", es "independiente”, del capital que pueda aportar otra persona o un consorcio de accionistas. Esta definición no garantiza, no obstante, que su criterio de selección sea necesariamente "independiente" de los condicionamientos de mercado.

Algunas pequeñas editoriales, de baja proyección de ventas, vienen, además, insistiendo en una demarcación más fina. Así, en el sitio de la editorial con sede en España Esto no es Berlín se lee: "somos conscientes de que será difícil posicionarnos como una alternativa a los grandes grupos editoriales y a las editoriales independientes que se han desentendido de la responsabilidad social que conlleva publicar libros. Pero persistimos y crecemos". Mientras que los editores de Economías de guerra reclaman que "Es necesario un trabajo de clasificación ya que algunas editoriales independientes han desarrollado la tarea política y hay otras que simplemente son empresas comunes y corrientes" (“Editorial Economías de guerra" 89).

López Winne y Malumián, por su parte, ofrecen una fórmula en los siguientes términos: "una editorial independiente [e]s la que tiene su norte enfocado en la construcción de un catálogo de calidad pero sin descuidar la mirada sobre la rentabilidad del proyecto. Persigue la autosustentabilidad y no depende de cualquier aporte de capital que provenga de fuera de su actividad editorial" (6). El problema de esta definición, a mi entender, radica en que carece de una variable diferencial de espesor, pues estos mismos atributos se podrían utilizar para definir a los grupos transnacionales: por lo pronto, si se da crédito a las frecuentes aseveraciones de Herralde, a Anagrama, pero también, por ejemplo, a Alfaguara en tanto que es una editorial rentable, autosustentable y con un catálogo que no se puede tildar de “descuidado" o, incluso, “de baja calidad”. Este tipo de conceptualización -puedo deducir- se desprende en cierto modo del modelo acuñado por Bourdieu y fracasa, en última instancia, porque se resiste a abandonar como marco de comprensión los límites de la racionalidad profesional característico de la industria cultural establecida. Las editoriales emergentes, pero decididas a insertarse en el circuito comercial, se van a autorepresentar y presentar, de acuerdo con la propuesta de Bourdieu, como alternativas antes interesadas por el "catálogo de calidad" que por el éxito de mercado. Una vez admitidas, no obstante, van a tender a desplazarse hacia una zona cada vez más próxima al polo heterónomo; este sería, según el esquema de Bourdieu (“Una revolución...”), el caso de Gallimard. Este proceso, que permitiría identificar un proyecto editorial solo como temporalmente independiente, es decir, hasta que consiga afianzar su capital cultural y económico acumulado, se resolvería, siempre e indefectiblemente, dentro de los límites del profesionalismo, según lo concibe la industria editorial convencional, es decir, 
economicista. ${ }^{5}$ Creo que una definición más exacta, que permita dar cuenta de condiciones observables en América Latina hoy, debe recurrir, por lo pronto, a herramientas que se aparten del modo de gestión "profesional".

Una definición frecuente de independencia suele ser por negatividad. Cito una de José de Souza Muniz Júnior que examina los campos brasilero y francés y que, en principio, se aproxima a la que sería mi propuesta. Dice:

Con este telón de fondo [la concentración], se forja la idea de editor "independiente" como aquel que, permaneciendo al margen de esos grandes grupos, mantiene total autonomía sobre la formación de su catálogo y privilegia la calidad en detrimento de la rentabilidad. La actuación de los editores así caracterizados es tomada, entonces, en clave positiva como territorio inmune o, por lo menos, resistente a tales transformaciones estructurales del mercado editorial y luego, como salvaguarda de la calidad y la diversidad en el mundo del libro. Por lo tanto, lo que nos parece nuevo, en este debate, en relación con las discusiones ya existentes, es que se crea una categoría ética que pasa a representar un polo de resistencia a esos efectos. El surgimiento de esta terminología señala, entonces, no solamente la percepción más o menos difundida de ciertos clivajes dentro del campo, sino también nuevas formas de identidad y de lucha. (146)

El problema con esta definición por negatividad -aunque tal vez ya acierta al ubicar el debate en un plano ético y político- es que, como va a advertir el mismo autor, del lado de los editores no alineados directa o indirectamente con los grandes grupos queda configurado un frente todavía heterogéneo cuyos elementos difícilmente pueden ser asimilados unos con otros. Para el caso de la literatura hispanoamericana, esto equivaldría a decir que una editorial casera y unipersonal como la ya comentada Funesiana, con sus tiradas de 50 ejemplares hechos a mano, tiene algo en común con Anagrama de Barcelona, con la editorial mexicana Tumbona conducida por un colectivo que promueve la publicación copyleft, con la emergente binacional Sexto Piso o la libertaria Traficantes de sueños de Madrid. Las cinco, a su manera, se diferencian en algún punto de los grandes grupos, pero sin duda no lo hacen del mismo modo. Por esta razón,

5 López Winne y Malumián hacen un esfuerzo, precisamente, para inscribir la edición independiente dentro de los marcos del profesionalismo economicista con lo que, a mi entender, no estarían delimitando correctamente su objeto: "Se entiende por profesional aquel que ostenta cierto saber sobre la práctica que realiza. Ese saber no debe estar reducido únicamente a los temas que más le agradan, sino que debe ser amplio y diverso para abarcar la totalidad de su práctica cotidiana. En pos de lograr un crecimiento sostenido se deben observar todas las aristas de la editorial, algunas claramente relegadas por los editores independientes. Los incluidos en este recorte [en el libro] poseen una mirada constante sobre los datos duros de su editorial, una búsqueda por entender qué librerías venden sus títulos y cuáles no, un intento por determinar las tiradas mediante datos y no sólo pálpitos, una mirada puesta en la evolución de sus ventas, etcétera. En pocas palabras, debe entrar de lleno en las cifras comerciales de su empresa” (13). 
algunas editoriales van a reclamar distinciones más finas como la que en su momento propusieron Astutti y Contreras: "la oposición independiente / multinacional no alcanza para explicar todo el campo, que en el interior de las editoriales independientes deben distinguirse también las editoriales, digamos, 'pequeñas”' (768). Y más adelante precisaban:

En cuanto a distinguir editoriales "pequeñas” en el interior de las editoriales independientes, ello obedece a la necesidad de llamar la atención sobre situaciones específicas que según lo entendemos- han contribuido a enriquecer y dinamizar notoriamente el espacio cultural. Específicas o diferentes, porque, para decirlo de un modo gráfico, los riesgos y los problemas que debe enfrentar una editorial como, pongamos por caso, Anagrama o incluso Pre-Textos, serán de otra naturaleza o de otro grado que aquellos con los que, en distinta medida, lidiamos editoriales como Adriana Hidalgo, Beatriz Viterbo, Simurg, o Paradiso, Tierra Firme, Alción, o Siesta, Zapatos Rojos, Tse-Tse, Vox, Melusina y El Broche. El criterio para definirlas sería el de que, además de su infraestructura más o menos pequeña en cada caso, e independientemente del volumen y de la proyección de su producción cultural, se trata de editoriales cuyo catálogo está compuesto en su mayor parte por títulos de tirada mediana o mínima, que rara vez llegan a 3000 ejemplares y cuya expectativa de venta oscila entre los 700 y los 1000 ejemplares (en algunos casos 300), y esto, a lo largo de algunos años. (770)

Es también este recorte apresurado el que ha conducido, incluso, a anular la categoría o, como señala Daniela Szpilbarg, a rechazarla: "hemos observado que en la última década ha comenzado a tomar forma y peso un modo de referirse a cierto segmento de las editoriales de literatura, como 'editoriales independientes'. Término equívoco, en la mayor parte de los casos ni siquiera aceptado por los editores llamados de ese modo, este fenómeno ha suscitado una reconfiguración del espacio editorial literario" ("Editoriales artesanales...”).

De acá también que José de Souza Muniz Júnior introduzca más adelante una distinción en los siguientes términos:

Para los “independientes" de LIBRE [la organización gremial que agrupa editores independientes de Brasil] (o, por lo menos, para aquellos que hablan en su nombre), esta denominación es una manera de diferenciarse de las grandes editoriales, particularmente de aquellas ligadas a poderosos grupos económicos y volcadas a los best-sellers. Sin embargo, tales editoriales se piensan como empresas profesionales y luchan por el derecho de competir con las majors en condición de igualdad, sea en el mercado privado, sea en las compras públicas de libros. En contrapartida, para la mayoría de los pequeños feriantes, ser una empresa editorial tradicional no está en el horizonte, y la "independencia” tiende a asumir el sentido de "alternativo", "artístico" o "artesanal”, es decir, de un quehacer que jamás sería posible en las editoriales comunes, por más chicas que sean. (154-155)

La distinción temprana - diría, todavía intuitiva- de las editoras de Beatriz Viterbo, comienza, así, diez, quince años más tarde a ser refinada: las "editoriales 
independientes pequeñas”, que producen “tiradas medianas o mínimas”, se diferencian, por lo pronto, de las que sí tienen proyecciones de "profesionalización”, de ampliación de la infraestructura productiva y de mercado, es decir, de las que, en términos de Bourdieu, aspiran a ocupar otras posiciones en el campo y en el sector editorial tradicional.

También Damián Tabarovsky, el escritor y editor de Mardulce, interroga el concepto de "independencia" y lo problematiza. El punto clave, según sus postulados, responde a la pregunta por independencia de qué:

al mismo tiempo que, por un lado, en los grandes holdings desaparece la figura del editor, esa estampa resurge en toda clase de editoriales pequeñas y medianas, chicas y más chicas, autodenominadas independientes. Independiente, por definición, es un término relacional. Se es independiente de algo, de alguien. ¿Independientes de quién o de qué son las editoriales independientes? Obviamente son independientes en el sentido de que no pertenecen a ningún gran holding. Pero eso no las vuelve necesariamente más dignas.

(Arias/Schmukler)

De estas propuestas, interrogantes y provocaciones se puede extraer una definición de "independencia" algo más refinada, una que, me parece, conviene que sea afirmativa. Una editorial independiente sería, entonces, una que problematiza las normas de funcionamiento del régimen heterónomo, lo que, básicamente, es lo que está contenido en la definición más extendida de “profesionalización”. La edición independiente es, por eso mismo, "artesanal"6: no "depende" de los hábitos de consumo establecidos, no "depende" de la demanda, no "depende" de una red de distribución o de un aparato de promoción mediática y no "depende" de los proveedores de materias primas "prometedoras" que son los agentes literarios. Y no "depende", paradójicamente, ante todo porque no cuenta con los recursos económicos necesarios para financiar esas redes de dependencia.

Bourdieu, en su artículo "Una revolución conservadora en la edición” de 1999, pone en evidencia cómo la prestigiosa editorial Gallimard mantiene un aura vinculado a una autonomía originaria que, si se examina en detalle su modo de gestión, hace tiempo se ha diluido. Lo mismo vale, y este caso interesa acá

\footnotetext{
6 La tradición de los folletos nordestinos de Brasil, como también propone Palmeiro, bien puede ser considerada un antecedente de la edición artesanal, en tanto desmarcada de la industria editorial profesional, que estoy tratando de conceptualizar. El folleto $A$ literatura de cordel (2002), precisamente, lo constata y expresa en su propia materialidad. En la página legal de este folleto, donde los libros habitualmente registran el tipo de licencia, el ISBN, la constancia del depósito en bibliotecas y otros datos, no hay mayor información que una referencia a la colección de la que forma parte - “Cartilha da Cultura Popular”-, la afirmación de que se trata de un "Livro Artesanal", un número de teléfono para hacer pedidos y una recomendación de citación que remarca la referencia "Produção artesanal".
} 
particularmente, para Anagrama. Como ya he sugerido, Anagrama es un ejemplo claro de editorial no-independiente ya que su modo de gestión, su lenguaje y la lógica, no se distingue en nada del de Planeta o Alfaguara. ISBN, agentes, Feria de Frankfurt, contratos, derechos, distribución, rentabilidad, premios, los términos más caros al mercado y más ajenos a la literatura en su sentido, digamos, "adorniano" son parte constitutiva de su modo de gestión. Una editorial independiente en sentido estricto -con lo que propongo seguir utilizando la categoría, pero de manera restringida- va a someter a juicio y a una eventual reformulación creativa las pautas de mercado; va a interrumpir, por lo menos en alguna instancia de la cadena productiva, -y con esto abandonamos el nominalismo para ubicarnos en el plano concreto de lo procedimental- la lógica de gestión de la industria cultural transnacional: "La llamada 'independencia”" dicen, por ejemplo, los editores de Inubicalistas- "para nuestra editorial, consiste en practicar conductas ajenas al mercado (neoliberal, como se plantea hoy en día), en cada una de las etapas de la edición" ("Ediciones Inubicalistas" 99). Y los de Alquimia Ediciones:

\begin{abstract}
Entendemos que una editorial es independiente cuando las políticas que establece para realizar todo el proceso de edición y producción de un libro, se diferencian de las prácticas del mercado transnacional, y no estén supeditadas a fines comerciales y/o filiales. [...] nos parece fundamental que una editorial independiente [...] entienda el proceso de edición como un trabajo político y a la vez artístico.

(“Alquimia Ediciones” 15)
\end{abstract}

Así, al sabotear los principios que rigen el sistema dominado por la lógica heterónoma -con lo cual también convendría admitir el carácter gradual antes que absoluto de la independencia-, la edición deviene activismo y una editorial independiente va a adquirir un insoslayable cariz político, es decir que, -y esto tiene que ser subrayado- como parte de un programa al mismo tiempo cultural y político, una editorial independiente cuestiona con sus prácticas -no solo con su discurso- total o parcialmente los mecanismos concretos de la producción industrial de literatura. ${ }^{7}$

7 Nótese que no es tanto la ruptura con el mercado en sí como el rechazo de una lógica de gestión lo que estaría definiendo la independencia. Esta distinción también permite reforzar la idea de que las editoriales emergentes gestionadas bajo las premisas procedimentales de la industria editorial concentrada no podrían ser consideradas exactamente independientes, sino en desarrollo. Al respecto, escribe Luigi Amara: "Nos parece muy importante no pensar una editorial independiente como las de la década de 1970, que eran independientes del Estado e incluso contestatarias al poder. Más bien buscamos ser independientes de la lógica del mercado. Obviamente no contra el mercado en cuanto a tal, porque los libros se venden, pero sí contra esa lógica que busca un crecimiento hipertrófico, que quiere novedades cada vez más rápido, que considera la periodicidad del libro cercana a la del yogurt y que no entiende que el ritmo del libro 
Pues bien, en efecto, desde mediados de los años 90 ha habido en América Latina, y particularmente en Argentina, un florecimiento de editoriales de baja proyección de ventas y distribución que a falta de mejor nombre suelen incluirse, dentro de un paquete mayor, bajo el paraguas conceptual "independientes". Sus publicaciones circulan, sin embargo, a escala siempre relativamente reducida, por regla general, en tiradas no mayores a 300 ejemplares, sin presencia en librerías, más que algunas muy especializadas, y sin mediación de agentes literarios. No suelen pagar adelantos de ningún tipo, en casos -como Tumbona, Inubicalistas, Determinado Rumor, THC Editores, Cinosargo, Nada Editores y, en España, Traficantes de sueños- liberan sus pdfs en internet y algunas ni siquiera llevan registro ISBN de sus títulos o realizan el depósito en bibliotecas estipulado por ley como todas las cartoneras, Belleza y felicidad, Neutrinos, Ediciones Bizarras o Ediciones Perro de puerto-. Se posicionan, además y abiertamente, contra la propiedad intelectual del modo que la promueve y alienta la industria cultural: "Cuestionamos el derecho de autor" -afirman los editores de Hebra- "cuando este entorpece la difusión del objeto literario que, por serlo, es material social" ("Ediciones Hebra" 92). ${ }^{8}$ Se trata, por estas razones, de una estructura productiva no-profesionalizada o semiprofesionalizada, sin mediaciones, con una cadena de agregado de valor reducida o deficiente, que, además, suele concentrar las diferentes especializaciones típicas de la estructura editorial "profesional" en una sola persona o un pequeño colectivo. Pero, en contrapartida, justamente por esta independencia de la lógica heterónoma, por sabotear la gramática del consenso entre mercado y producción cultural e insertarse en un circuito informal -no reconocido, ni reconocible-, estas editoriales se pueden permitir publicar -vamos a decir así- "lo que quieren” y generar, por consiguiente, un espacio radical para la experimentación, que voy a abordar en el próximo apartado. Anota Daniela Szpilbarg que

Estas editoriales pequeñas asoman con expectativas que no podrían ser calificadas de económicas y muchas veces, tampoco aparecen en los registros oficiales de editoriales.

es lento; pueden pasar años e incluso décadas para que un libro llegue a las manos del lector. Con esta postura que apuesta al largo plazo intentamos ser un bastión contra lo que hace del libro una mercancía más.

Vemos muchísimas editoriales, no sólo en México, que se autonombran independientes, pero que en realidad deberían considerarse editoriales pequeñas o en vías de crecimiento. Por ahora tienen pocos libros pero su aspiración última sería convertirse, si pudieran, en Random House. No son independientes de la lógica del mercado, no tienen problema en pedir cualquier tipo de apoyo estatal o federal, o de entrar a concursos de la SEP. Sólo se llaman independientes por su tamaño, lo cual no es ningún tipo de independencia” (68).

8 Véase también el volumen colectivo y de acceso libre en internet Contra el copyright (2008), publicado por Tumbona Ediciones como parte de su programa de activismo cultural. 


\begin{abstract}
Muchas de estas editoriales pequeñas producen con lógicas opuestas a las del mercado. Si bien no son importantes en términos de ingresos brutos, son simbólicamente importantes porque generan circulación de los autores y literatura predominantemente contemporánea y nacional, aunque hay algunas editoriales cuyas colecciones se encuentran armadas en base a un criterio de difusión de autores latinoamericanos. Por este motivo, muchas veces se ocupan de la recuperación de una cultura local acallada por el cada vez mayor dominio de las grandes casas editoras.

(“Editoriales artesanales...”)
\end{abstract}

Así, aunque su relevancia en términos de mercado, sea nula, aunque su posibilidad de puesta en circulación y creación de públicos sea intrascendente, poseen un doble valor simbólico que los estudios literarios no deben descuidar: constituyen, por un lado, el lugar donde la literatura, organizada en torno a un concepto de valor estético/político radical, "todavía es posible” y, por el otro, las únicas plataformas de expresión donde, en el marco de la actual fase de la globalización, la diferencia local periférica puede manifestarse.

La capacidad de producir este tipo de valor, estético, político y cultural, se va a sostener en un quiebre en relación con las consignas de la industria editorial convencional: "La intención, en definitiva, sería provocar la circulación de textos, e ir por fuera de los ámbitos y circuitos clásicos de la industria" (Szpilbarg ("Editoriales artesanales..."). Los textos de las literaturas locales, así, sí van a orientarse a la circulación, pero a una alternativa, nunca transnacional, aunque sí, en casos, translocal; esa circulación subterránea, del orden de lo microfísico y de la micropolítica cultural, a su vez, va a hilvanar un microcampo literario disidente, separado por un hemistiquio muchas veces infranqueable del campo mayoritario que se ha inclinado de manera orgánica hacia el polo heterónomo. El de las literaturas locales se convierte, así, en un circuito cerrado sobre sí mismo, con lo que el modelo de Bourdieu, al darse tal polarización, ya no permitiría conceptualizarlo. Precisamente para dar cuenta de este fenómeno, Matías Moscardi propone, con una fórmula tomada de la escena de los fanzines, hablar de "editoriales interdependientes", "es decir, que dependen unos de otros y no existen por sí mismos, de manera aislada y convencional. Por el contrario: forman una especie de comunidad o campo atomizado pero sin centro, distinto a la figura del campo literario que opera en la teoría de Bourdieu" (La máquina... 44). Si bien no va a desarrollar la idea, creo que, con esta observación, Moscardi toca un punto clave: que una zona de los campos locales, la que orbita en torno a las editoriales independientes (radicales, pequeñas, artesanales), se ha desentendido de una disputa por el significado de la literatura contra los grupos transnacionales y el polo heterónomo para ubicarse en un territorio distante del mercado. Aunque invisible, esa zona, de producción, de reflexión y de activismo político/cultural, sería hoy, de acuerdo con José Ignacio Padilla, la más dinámica y sugerente del subcontinente: 
Moriconi se ve obligado a mencionar un cuarto circuito [de lo literario]: el de la escritura y publicación fuera del mercado, que él asocia a las ONG y a las iniciativas de la sociedad civil. En rigor, en ese circuito ya no estaríamos tratando con la literatura, siempre y cuando consideremos "que el concepto de literatura implica la circulación en un mercado del libro y la condición profesional de producción de ese libro del lado del autor o autora, que son los actores principales del sistema" (193). Pero yo creo que es este circuito, junto con el de la "vida literaria” el más interesante para pensar y describir la América Latina literaria.

(“¿Circuitos...” 30)

En esta zona, al "permitirse descuidar la rentabilidad del proyecto”, la edición no toma -no puede tomar- jamás la forma de una empresa convencional. Antes, y esto sin que implique un perjuicio de la sustentabilidad, ${ }^{9}$ son emprendimientos al mismo tiempo estético-políticos, que, por eso mismo, corresponde ubicarlos en un circuito diferente y separado del que configura la industria cultural:

En la mayoría de los casos, estas pequeñas editoriales están dirigidas y financiadas por escritores que pocas veces ven sus actividades editoriales como contrapuestas al proyecto creador, sino que bocetan nuevos modelos de intervención artística e intelectual, generando en la práctica un tipo de activismo cultural donde la escritura y la edición se solapan. Su inclusión dentro de la categoría de "industrias culturales” es, asimismo, problemática. Más bien, podría decirse que los proyectos editoriales que nos interesan [...] se encuentran en una situación liminar, y funcionan como síntomas de ciertos procesos de desindustrialización en la factura de los objetos propios de ciertas zonas de la cultura literaria.

(Vanoli 162)

Al darse este fenómeno de corrimiento del circuito convencional ahora dominado por los grandes grupos, de atomización de los sistemas de producción de literaturas locales y, con ello, una suerte de retraimiento solipsista de la zona más autónoma de los campos locales, emerge un escenario donde las literaturas vernáculas, las menos "adoptables", raramente comparten espacios con la de (fácil) circulación

$9 \mathrm{Al}$ respecto de la sustentabilidad de un proyecto abiertamente posicionado frente a la lógica de mercado dominante, José Ignacio Padilla anota: "La librería, editorial y distribuidora asociativa Traficantes de sueños en el barrio de Embajadores, en Madrid, nos da un buen ejemplo. El local de la librería es un activo centro cultural en el que se organizan presentaciones, talleres y discusiones, y se ofrecen libros en la línea ideológica de la cooperativa (antisistema, teoría política, arte crítico). Simultáneamente se editan libros de alto nivel (ya llevan unos 75); sus autores participan del copyleft -licencias con diversos grados de flexibilidad para la reproducción de contenidos: se agradece la fotocopia y los PDF de los libros editados pueden descargarse gratuitamente, sin restricciones, desde cualquier país-. La asociación también distribuye y vende sus libros en la web. Es decir, este proyecto abarca diferentes aspectos del mundo del libro, como en el caso de los grandes grupos, pero desde una posición anticapitalista. Jamás he escuchado que Traficantes de sueños esté en crisis, ni que reclame protección del estado. Su legitimidad le es dada por su ideología y por la calidad de sus libros" (“Independientes" 253-254). 
internacional. En última instancia, se trata, como remarca José María Espinasa, el editor de Ediciones Sin Nombre, de mercados organizados en torno a objetos diferentes: "Y uno les repite una y otra vez: no se preocupen, no somos competencia, no queremos ser como ustedes, queremos seguir siendo como somos, nuestro tamañazo nos permite hacer los libros que queremos" (48). De mercados, de comunidades de lectura y de campos. Se trataría, para representarlo de algún modo, como si el campo de Bourdieu, en el marco de la actual coyuntura histórica y en la forma que toma en América Latina, se hubiera fracturado y, mientras que el polo heterónomo domina los grandes canales del circuito transnacional y sus ramificaciones nacionales, el autónomo dispone de dominios altamente localizados e indiferentes a la suerte de la literatura más o menos sincronizada con el mercado.

De acá, desde ya, no habría que concluir que todo lo que publiquen las editoriales artesanales independientes sea necesariamente válido en términos cualitativos -aunque el criterio "calidad” tampoco sería un variable diferencial decisiva-, pero sí que su lógica productiva da lugar a una experimentación y una disidencia formal ausentes en la literatura mundial. Es en el escenario local periférico, artesanal, precario -en todo caso semi o no profesionalizado-, por lo tanto, donde el frente autónomo, donde la literatura que problematiza la gramática del consenso, encuentra su espacio de potencial desarrollo. El corpus que conforman, en su conjunto, es uno heterogéneo, anómalo, disruptivo, difícil de conceptualizar con las herramientas de los estudios literarios convencionales; es el que, con un término prestado de Walter Mignolo, yo propongo denominar literatura pluriversal ("Más allá...”).

Y así, de manera tangencial, llego a la "bibliodiversidad”. Como adelanté, se trata de un concepto altamente institucionalizado del que se valen editoriales, 0 gremios editoriales, normalmente para ganar terreno en el mercado internacional. Cito, a modo de ejemplo, palabras de Pedro Francisco Villa Gamarra, exdirector de la Dirección del Libro y la Lectura de Perú, en el Catálogo de Editoriales Independientes del Perú del 2014 (publicado por el Ministerio de Cultura): "Promover la bibliodiversidad significa favorecer la circulación de ideas y autores, de oferta y nueva literatura en el mercado interno e internacional” (3). Extraigo de acá que la categoría pertenece al dominio extraliterario: define libros -con ISBN, copyright, etc.- que pueden ser vendidos como expresión de algún tipo de diferencia. "El concepto de bibliodiversidad" observa José Ignacio Padilla en esta misma línea- "es adaptado del de biodiversidad, que ya es en sí una mezcla de preocupación ecológica con capitalismo -la biodiversidad como un recurso estratégico explotable-. La bibliodiversidad es un capital al que se suma el afán multiculturalista” (“Independientes” 252-253).

Sin embargo, la diferencia que estoy tratando de conceptualizar, porque las condiciones de producción específicas bajo las que opera no lo permiten, puede 
ser que no tenga espacio, o acaso uno marginal, en el mercado, principalmente en el internacional, del libro, que no sea compatible con su lógica dominante. La bibliodiversidad que me interesa, la única $-\mathrm{y}$ con esto hago un esfuerzo por preservar el término-, es, por lo tanto, la que también acepta libros, por decirlo de algún modo, N/N, sin ISBN, cartoneros, anómalos, hechos a mano o liberados como pdf. Sostiene Padilla -y, sin duda, acierta- que "la defensa de la bibliodiversidad no propone una alternativa al mercado ni hace una crítica de fondo del sistema capitalista de edición (alta rotación: más libros y con menores tiradas, cada vez). Sin embargo, existen alternativas: cooperativas, grupos de autogestión y el copyleft" (“Independientes” 253). Creo, por mi parte, que esas alternativas, las que problematizan el consenso entre literatura y mercado, tal vez pueden ser incluidas dentro del alcance conceptual de una bibliodiversidad ampliada y radical, una amparada en la mejor y más crítica tradición humanista y no en las prerrogativas de mercado.

Creo -y en esto se va a centrar el próximo apartado- que en los libros que mayor resistencia le ofrecen a la lógica heterónoma, los que prefieren no aceptar sus pautas de funcionamiento, en esos que a veces no se parecen a libros, están contenidas auténticas diferencias estéticas, políticas y culturales. Y en su conjunto, valga decir, la diversidad. Una diversidad garantizada, ante todo, por la heterogeneidad de las condiciones de producción y de los horizontes de expectativas de donde surgen esos productos, es decir, como proponen -y sintetizanlos editores de Inubicalistas, una diversidad que se articularía a partir de inscripciones geoculturales concretas:

Por otra parte está el rol territorial que pueda tener una editorial, como garante de la diversidad. Así es como muchas editoriales alejadas del centro político y económico, han optado por escalas de producción artesanal, pasando por el lado de los marcos legales del libro, para publicar autores que de otra manera serían marginados de una posible circulación, un "silenciamiento de voces", que claramente atenta contra ese ecosistema de ideas llamado diversidad. Poéticas que no interesan a un discurso centralista, historias locales, narrativas que dan cuenta de sensibilidades ajenas al ruido del neoliberalismo, cosmovisiones alejadas de la industria cultural, en fin, ideas que no pasan por el filtro de la cultura masiva que finalmente son las que reflejan el estado de salud de una sociedad.

("Ediciones Inubicalistas" 99)

De modo que, y en resumen, lo que las editoriales independientes artesanales pueden aportar a una bibliodiversidad heterodoxa, descentrada, políglota es, en realidad, una doble alternativa: tanto a la lógica de gestión heterónoma como a la estandarización que produce la selección de las literaturas del mundo desde pocos centros de gestión mundial. O, como lo formulan Astutti y Contreras, que 
Si la segmentación del mercado y la homogeneización del gusto son las herramientas de los grandes grupos para obtener el máximo de rendimiento económico, la función de las editoriales independientes aparece, en principio, como la de garantizar la diversidad: no sólo la de asegurar un espacio para la expresión de las producciones "locales" -que escapan al perfil de los productos "internacionales"- sino también la de abrir -o preservar- un espacio para la pluralidad de las manifestaciones culturales -que escapan a la estandarización que requiere un imperativo exclusiva o prioritariamente comercial. (768)

De lo expuesto hasta acá puedo concluir, además, que la edición (y la literatura) independiente es hoy de carácter eminentemente local. A veces, nacional, a veces, regional, a veces, únicamente barrial, pero difícilmente "mundial" o transnacional. Solo porque este nivel de gestión tiene un costo económico que la literatura por sí misma -acaso, por suerte- no puede solventar. 